

\section{DISCLAIMER}

This report was prepared as an account of work sponsored by an agency of the United States Government. Neither the United States Government nor any agency Thereof, nor any of their employees, makes any warranty, express or implied, or assumes any legal liability or responsibility for the accuracy, completeness, or usefulness of any information, apparatus, product, or process disclosed, or represents that its use would not infringe privately owned rights. Reference herein to any specific commercial product, process, or service by trade name, trademark, manufacturer, or otherwise does not necessarily constitute or imply its endorsement, recommendation, or favoring by the United States Government or any agency thereof. The views and opinions of authors expressed herein do not necessarily state or reflect those of the United States Government or any agency thereof. 


\section{DISCLAIMER}

Portions of this document may be illegible in electronic image products. Images are produced from the best available original document. 


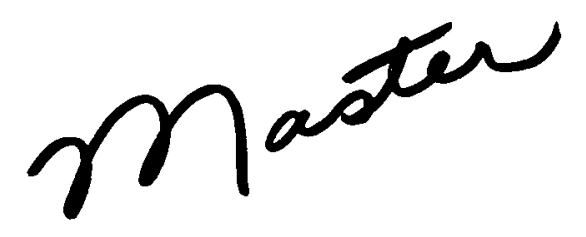

BNL-51199

UC-13

[General, Miscellaneous, and Progress

Reports (Nonnuclear) - TID-4500]

\title{
A COMPARATIVE REVIEW OF THE \\ TIME-STEPPED ENERGY SYSTEM OPTIMIZATION MODEL (TESOM) AND THE \\ IEA MARKET ALLOCATION MODEL (MARKAL)
}

April 1980

\author{
ANDY S. KYDES, Head \\ ENERGY DATA AND MODELS GROUP
}

NATIONAL CENTER FOR ANALYSIS OF ENERGY SYSTEMS

DEPARTMENT OF ENERGY AND ENVIRONMENT

BROOKHAVEN NATIONAL LABORATORY

ASSOCIATED UNIVERSITIES, INC.

UNDER CONTRACT NO. DE-ACO2-76CHO0016 WITH THE

UNITED STATES DEPARTMENT OF ENERGY

This book was prepared as an account of work sponsored by an agency of the United States Government. Neither the United States Government nor any agency thereof, nor any of their employees, makes any

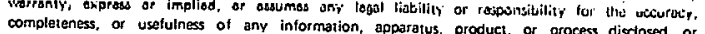
rearesents that its use would not infringe privately ouned rights. Reference herein to any specific 


\section{DISCLAIMER}

This honk was prepared as an arrnunt of work eponoorod by an ageney of the Unilud States Government. Neither the United States Government nor any agency thereof, nor any of their employees, makes any warranty, express or implied, or assumes any lugal liabiliiy u1 ıespunslbllity for the accuracy, completeness, or usefulness of any information, apparatus. product, or process disclnser, nr represents that its use would not infringe privately owned rights. $\bar{R}$ eference herein to any specific commercial product, process, or service by trade name, trademark, manufacturer, or otherwise, does not necessarily constitute or imply its endorsement, recommendation, or favoring by the United States Government or any agency thereof. The views and opinions of authors expressed herein do not necessarily state or reflect those of the United States Government or any agency thereof.

Printed in the United States of America

$$
\text { Available from }
$$

National Technical Information Service

U.S. Department of Commerce

5285 Port Royal Road

Springfield, VA 22161

Price: Printed Copy $\$ 4.00 ;$ Microfiche $\$ 3.00$ 


\section{CONTENTS}

Abstract.............................................

I. Introduction....................................... 1

II. The Time-Stepped Energy System Optimization Mode1 (TESOM).........

III. The Market Allocation Model (MARKAL).......................

IV. Intermode 1 Comparis ons ...............................

References..............................................

Appendix A.............................................. 


\section{Abstract}

This report describes the two principal energy system models used in the Nationa 1 Center for Analysis of Energy Systems at Brookhaven National Laboratory and contrasts their important differences.

\section{Acknowledgements}

I gratefully acknowledge the contributions of Vance Sailor and Douglas Hill who have conveyed to me information on new refinements to the MARKAL model of which I was unaware. I a lso wish to thank Jerome Lamontagne for his editorial advice which improved the content of this document. Sole responsibility for this document, however, rests solely with the author and does not necessar1ly represent the opinions of others.

A special thank you to Mary Lou Weis for her assistance in editing, coordinating and typing this report. 


\section{Introduction}

The scope of energy systems analysis has broadened to include not only energy-economic interactions and their implications for policy planning but also social concerns (e.g., environmental degradation) and security requirements. (e.g., levels of oil imports) and their interactions with energy use and the economy. Evidently, the quality of an energy system configuration can no longer be judged solely by economic considerations. Social concerns and security currently compete with the goal of system cost minimization. It has become essential to Identify and employ approaches and a systems framework which facilitate the evaluation and characterization of an energy system by multiple criteria. Further, social concerns of ten induce a level of complexity which mandates a hierarchical approach to the systems analysis; appropriate models must be utilized in an integrated framework. This approach permits modularity in the analysis when high resolution in certain components is required and permits reaggregation of results from these modules when an analysis of their impacts on the evolution of the national energy system as a whole is required. The TESOM and MARKAL models are crucial components of this energy systems framework.

\section{The Time-stepped Energy System Optimization Mode1 (TESOM)}

TESOM [3] was designed to assess the impact of new generic technologies on the evolution of the national energy system within a time-sequenced energy system context. The model has also been used to do multi-objective analysis, cost-benefit analysis, and technology assessment.

The BNL mode1, TESOM, is a national, energy system model based on Brookhaven's Reference Energy System (RES). The RES provides a complete and consistent accounting system, in physical units, for energy flows through energy technologies. With appropriate conversion efficiencies, the RES proceeds from the extraction or importation of primary energy resources and products, through refining and the various stages of energy conversion, transportation distribution, and storage, to the consumption of fuels by end-use technologies corresponding to a particular energy service demand. Within the RES, emphasis is placed on a comprehensive technological structure relating energy flows which enter the system (oil, gas, coal, uranium, solar, etc.) to the relatively nonsubstitutable, functional, energy services that are the final product of the flow (space conditioning, motive power, process heat, 1ighting, etc.). Thus, the RES framework reflects the full, feasible range of interfuel and technological substitutability.

TESOM is usually run sequentially with five-year intervals from 1980 to 2025. The time intervals are user input. For each year the model oprimally allocates energy resources and products and selects the optimal mix of supply, conversion, and demand technologies according to least-cost economic criteria to satisfy a specified set of energy service demands. Resource supply representations are specified as long- or short-term supply curves or fixed prices and availabilities by year. The TESOM model provides a "vintage" representation of the nation's energy system in that the optimal levels of the decision variables for any time-period are-determined from: 
- The optimal levels established for previous periods;

- The retirement and deterioration rates, the lifetimes, and the associated costs of vintage capital stocks; and

- The economic and technological factors affecting the feasible levels of the decision variables for the period under investigation (e.g., decline rates, supply elasticities, cumulative resource avallabilities, market penetration considerations, etc.)

Mathematically, the model is formulated as a sequence of expanding, linear programming formulations of the RES--one for each time period. For a given time period, the solutions derived for earlier periods are incorporated into the sequenced formulation along with assumptions regarding retirement and decline rates, average lifetimes, age-dependent conversion effirfenrfes, ${ }^{1}$ ant. facturs, DGH cusls, and Llie caplial charges for the stocks-in-place. I'hen, at least-cost or other quantitiable criteria, the energy demands are satisfied in accordance with the supply expansions and increased penetrations that are atcainable for the period and the net avallabilities from the evolution of the energy system to date. In meeting future energy demands, TESOM has a memory of the net availabilities from the past, augmented by avallibilities attainable in the near-term. The updating and sequencing procedures are repeated until solutions for the entire time horizon are determined.

TESOM provides a detalled representation of the electric sector. A set of demand types (e.g., base and intermedlate loads, off-peak, heating, cooling, etc.) are defined. Each demand type has its own set of characteristics regarding its stochastic behavior and its seasonal (winter, summer, springfal1) and daily (day, night) loading. Required capacity is governed by the highest, total peak demand which occurs during some time of the year and day. By appropriately loading the electric energy service demands onto the various (or, in some cases, corresponding) demand types and, subsequently, loading these demands onto the various season-day combinations, the helght of the total peak for each season-day is determined. Required capacity is simply the maximum of the individual season-day peaks with allowances for transmission and distribution losses and reserve margins. This feature permits the introduction of load management considerations into the problem formulation as the load duration curve is, in part, exogenously determined from the detailed demand characteristics and their implications for the electric system.

TESOM also contains a number of features designed to smooth the intertemporal transitions indicated by the sequence of solutions. Among these are the mechanisms for pricing and adjusting the availabilities of vintage stocks and an improved market penetration algorithm which avoids the "bangbang" characteristic of linear programming models. To the extent that the ayse of a vintage stock is not beyond its economic lifetime, the annualized capital charges for the technology impose a cost on the system. Thus the fixed costs associated with previous investments are incurred irrespective of whether or not it is optimal to operate, partially or fully, an older technology. "Unrealistic" displacements of relatively inefficient vintages are discouraged when the associated variable costs of alternative stocks are combined with the fact that immediate write-offs are precluded. 
The procedure for market penetration requires, as input, "optimistic" penetration levels for each technology in each year. The penetration algorithm then incorporates the marginal values, implementation rates, and lag times from previous periods as well as the technological and market characteristics for the current period into the determination of more realistic bounds for the activity levels. The user-specified bounds are adjusted endogenously to account for the previous penetration and attractiveness of the technology.

\section{The Market Allocation Model (MARKAL)}

MARKAL was developed by a cooperative effort of the International Energy Agency (IEA) and the U.S. Department of Energy (DOE) to facilitate studies of: (a) the effects of new technologies in meeting anticipated future energy service demands; (b) the relative attractiveness of new technologies (ranking technologies for allocating limited R\&D funds).

The development of the MARKAL model was motivated, in part, by the need to determine the energy policy and strategy options by member nations of the IEA to cope with uncertain futures of energy resources, demands, costs and technological availabilities.

MARKAL is a single country (region) demand-driven, time-phased, linear programming model designed to analyze the evolution of supply/distribution systems over a given time horizon. MARKAL, like TESOM, is also based on the RES. All supply availabilities, demand, technologies, etc., are assumed known for the entire time horizon, unlike TESOM. See reference 1 for a complete description of MARKAL.

MARKAL is the result of an intensive international cooperative effort by staff of the International Energy Agency (IEA), the National Center for Analysis of Energy Systems, and KFA* in Julich, Germany. The hybrid model, MARKAL, captures the strengths of DESOM [4], a former dynamic energy systems model at Brookhaven, and the KFA model and incorporates new modeling refinements. In particular, MARKAL combines demand side flexibility and interfuel substitution potential of DESOM with the supply side flexibility and process resolution of the KFA model.

MARKAL is categorized as a dynamic (time-dependent) energy system optimization model. Each period's activities are connerted to those of the past and future through explicit capacity and growth constraints. The particular mathematical structure used ensures that all information regarding the past, present and future are used simultaneously to optimize the objective selected. In this sense, the MARKAL model can be loosely regarded as "clairvoyant" where as the TESOM model can be classified as a "rational expectations" model.

Given the inputs and constraints, MARKAL selects an optimum energy system trajectory over the time span specified. Optimization can be done with respect to various quantifiable attributes of the system and the demand and supply sectors can range from highly aggregated to highly disaggregated, depending on the quality and quantity of data avallable.

The model permits a maximum of 16 equal time steps. The length of the time interval of each step can be selected. However, in most applications

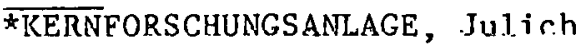


MARKAI, is used in 9 time steps at 5-year intervals spanning the period from 1980 to 2025. Time period $(T)=1$ would cover the 5 -year interval from mid1977 to mid-1982 centered at the beginning of 1980 .

MARKAL represents a new significant advance for dynamic linear programming energy models. Significant new characteristics of MARKAL include:

(a) The representation of scheduled and nonscheduled plant shut-down are more detalled.

(b) Revised nuclear fuel cycle characterization of intra and interperiod lags in construction and stockpiling of nuclear material.

(c) The data base required is directly generated by a data base management system (System 2000) and hence provides an automated preparation of MARKAL inputs.

(d) An explicit oil refinery representation with a range of potential (and feasible) product mixes available has been modeled. MARKAL sclcces the optimal (technologieally leasille) wls of ull fractions to satisfy energy service demands (over the entire time horizon).

(e) New hydroelectric and pumped storage characterizations reflect seasonal vartatlons in avallability, e.g., hydroelectric may be (and is) totally unavailable during the winter while some electricity may be available for export during the summer (Austria).

(f) MARKAL also provides a detailed representation of the electrical sector with demands for electricity being distributed among 6 time of day and seasonal blocks. In addition, it is possible to constrain specified generating facilities to operate only in the baseload mode and unreliable generating sources (wind, wave, solar etc.) can be precluded from contributing to meeting peak demand requiremente.

(g) Conversion facilities are automatically retired from service at the end of a specified technical lifetime.

(h) Coupled production and co-generation of heat and electricity are modelled.

The MARKAL model has been used to analyze the energy system of fifteen countries and the collective European Economic Community (EEC). The fifteen countries have completed analysis for about 16 standard scenarios which reflect various combinations of assumptions about policy options and global constraints. Thus MARKAL has become a standard model enjoying wide-spread international application.

MARKAL is thoroughly documented. A prospective user can quickly priepare a problem and run it using the BNL computer facilities within 2-4 weeks after arriving at BNL. The BNL-version of the MARKAL model has been successfully transferred to Spain and Japan using CDC Cybernet facilities. 


\section{Intermodel Comparisons}

Both models can be used to analyze

(a) the effects of new technologles in meeting anticipated future energy service demands;

(b) the relative attractiveness of new technologies (ranking technologles for allocating limited R\&D funds);

(c) the sensitivity of the evolution of the energy system to initial date of availability of technologies, their maximum permitted capaclty growth rates and the cost of the new technologies;

(d) the timing of capital requirements and their economic-energy impacts;

(e) the effects of long-range conservation practices on the energy supply/demand distribution systems;

(f) technology assessment with respect to prioritized hierarchical criteria. Three significant criteria for the United States can be classified as security, cost and "social concerns." One potential criterion for maximizing security is minimizing imports; a surrogate for cost is the discounted present value of the energy system. "Social Concerns" has meant an aversion to (i) coal consumption, (ii) use of highly centralized energy systems, (iii) excessive and/or abusive land-use, and (iv) exposure to radiation. Several surrogates have been suggested; (i) $\mathrm{CO}_{2}$, (ii) radiation, (iii) a weighted environment indicator of selective effluents, and (iv) net heat release by nonrenewables.

There are several important differences between MARKAL and TESOM which need to be reviewed to understand the utility of each model. The principal differences are in the:

- treatment of "Information" for the future in decision making;

- objective functions - the treatment of cost;

- treatment of nuclear fuel cycle and hydropower;

- size and difficulty of solving the problem;

cost of solving the problem;

ability to integrate the modeling system, to include economic feedbacks;

- Incorporation of the dynamics for market penetration of energy technologies. 
Treatment of "Information"

The treatment and use of "information" about the past, present, and future is one of the striking differences between TESOM and MARKAL and reflects fundamental differences in how decisions are made. MARKAL is designed to answer the question: What is the optimal course of action, given perfect knowledge? This objective does not pretend to be the way consumers make decisions.

The mathematical formulation of MARKAL 1mplies the use of all information about the past, present, and future in decision making. That is, the demands for energy services through time, the time and magnitude of any energy dislocations, the dates of commercial avallability of all technologles, all longterm resource cost curves, etc. are used to derive the optimal solution throughout time. One implication is that all oil embargoes or price jumps in energy are foreseen and patterns of energy use are altered in anticipation of these disruptions to optimize any given objective.

The mathematical formulation of TESOM implies the use of information about the past, present and expectations about the future prices of resources in decision making. Nothing about the future is assumed known in advance. In each period, trends in resource prices are computed and used to extrapolate the future prices. The decisions for each period are based upon the vintaged equipment acquired from the past (and associated costs), the current demand for energy service and the resource price expectations about the future. In particular, the resource price for a particular fuel used is the current period price plus an increment to reflect past trends. The increment weighting factor is a user input. Preliminary experiments with TESOM suggest that the level of assumed expectation is very important in the tining and rate of penetration of coal synthetic and other advanced technologies. This suggests that public relations and awareness of price trends can alter substantially the acceptance of new capital intensive technologies.

\section{Treatment of Costs in the Objective Function}

Although the components (inputs) of cost are virtually identical between the two models (see Appendix A), the measurement of cost is quite different. Costs in MARKAL, like TESOM, as treated as costs to the nation as opposed to costs to the individual consumer. The cost objective in MARKAL, called "PRICE," is the discounted present value "cost" over the entire time horizon. That is, the cost is the sum of discounted annual system cost, investment costs minus the salvage value of the investments at the end of the time horizon.

Investment costs are charged to the beginning of the time period in which a unic becomes operational. iuel costs are charged annualiy during the period in which the fuel is consumed. All costs are discounted to a specified year and summed to give the present value for the entire system over the entire time span. The discount ratc must be speciffed. Sunk costs for existing facilities are not included.

An example may prove helpful. Suppose an investment, I, is made in 1995 for an SRC II plant and suppose a discount factor (i) of $6 \%$ is used, then the present value of the investment in 1980 dollars is $\mathrm{I} /(1+.06)^{15}$ or $.417 \mathrm{I}$. 
The TESOM cost objective function assumes that the majority of any investment will be borrowed, much like a home mortgage from a bank, and repayed in level constant dollar payments over the economic life of the device. In particular, if $I$ is the investment, $L$ is the economic life of the device and 1 is the fixed charge rate, then equal annual payments of $P$ are required over the economic life, $\mathrm{L}$, of the device, e.g.,

$$
P=\frac{i}{1-(1+1)^{-L}} * I
$$

The quantity $P$ is the required annual payment over the economic life of the investment and is charged to the installed capacity regardless of how the device is used by the energy system. All costs are given in a fixed year, usually 1975 dollars for TESOM.: The cost objective function is usually the annualized cost of capital investments plus the annual fuel and operating and maintenance costs. The annualized forced payment for capacity installed in the past is one factor in TESOM which inhibits "all or nothing" behavior. MARKAL does the same except the payments are not annualized. Resource prices for TESOM, as mentioned earlier, are computed by adding an increment, $w$, of the annual increase rate to the reference price $p(t)$; that $1 s$,

$$
p(t)=p(t)+w * \text { Annual Increase Rate }
$$

Treatment of Nuclear and Hydropower

The full nuclear fuel cycle is represented in MARKAL whereas the representation in TESOM is highly simplified. For hydropower, the potential for seasonal cut-offs of hydro-electric production is explicitly modeled in MARKAL, whereas seasonal availability must be approximated through a reduced availability factor in TESOM.

Costs of Solving the Problem, the Size and Difficulty of Solving the Problem

MARKAL for the U.S. has up to 3,500 constraints and 4,000 variables and costs from $\$ 75$ to $\$ 500$ per run. Results can be returned in about one day after submission. The data handling is organized through a commercial data base system (system 2000) and there is some data screening (verification) to help reduce typographical errors on input. The slze of MARKAL borders on the limits for size solvable with APEX III at Brookhaven National Laboratory.

TESOM begins with approximately 350 constraints and 400 variables and can grow to approximately 800 constraints and 900 variables by year 2025 . The cost for a comparable time frame can range from $\$ 50$ to $\$ 150$ per run and the results for the entire time frame also require about one day turn-around after subiaision. The data handling is through direct editing of relevant input files and separate data screening has not been developed.

\section{Ability to Integrate the Energy Model To Include Economic Feedbacks}

The MARKAL model has not been linked to any macro-economic growth model. The formal linkage of TESOM to the Long-term Inter-industry Transactions Model (LITM) of Dale Jorgenson Associates is theoretically posstble but has never been attempted. The TESOM model is currently linked to the LITM model in a semi-automated way through tie exchange of computer output tata files. 
Treatment of Dynamics of Market Penetration of Energy Technologies

MARKAL has four ways to limit market penetration: (1) upper bounds by period, (2) specified growth rates, (3) an upper limlt on incremental additions in any time period, (4) a "smoothing" function on capital investment in each technology, any or all of which can be used. The model can "flip-flop" between adjacent periods for small varlations in cost; that 1s some technology may enter and later leave the mix of optimal technologies for small variations in the costs and adjacent periods. An additional smoothing algorithm [5] could be incorporated but has not since this would require an iterative solution system with several reruns of MARKAL for each scenario.

For TESOM, market penetration of all technologies is a dynamic process. The optimistic penetration levels for each technology and period are input but these are dynamically adjusted, based on behavioral lags and attractiveness indicles computed from past solutions. "Flif-flops" are also diecouragcd by the explicit vintaging of energy equipment purchased in previous periods. Capital charges for these must be paid throughout their economic life, regardless of how they are used.

Overview Comparison

Both models can be used to do cost-benefit analysis and multi-objective analysis. TESOM, however, is more of a simulation tool than MARKAL. MARKAL is purely a normative model which is perhaps better suited for long-range strategic planning than TESOM; MARKAL can be better used to identify "best" long-range strategies under various quantifiable criteria. These best states are not likely to be achievable, however because perfect information is never available. The value of an optimal solution from MARKAL is in the knowledge that it is the best, not that it is neressartly achievable.

The optimization framework in both models is ideally suited for performing cost-benefit analysis, multi-objective analysis, and technology assessment at the macro level where technologles are treated generically. The solution techniques for linear programming problems (LP) are specifically designed to do parametric analysis of both engineering cost and avallability parameters. The multi-objective analysis techniques are most advanced for LP formulations (and easiest to understand). The LP provides an easy framework for analyzing, for example, the trade-offs between security, cost and investments at a macro level and the value of coal synthetic R\&D programs to the particular objectives identified. Reference 2 provides several examples of multi-objective applications of these energy system models. 
1. H. Abilock and L. G. Fishbone, User's Gulde for MARKAL, BNL 27075, December 31,1979 .

2. A. S. Kydes, "The Brookhaven Energy System Model, Its Variants and Uses," BNL 50873, May 1978.

3. A. S. Kydes and J. Rabinowitz, "The Time-stepped Energy System Optimization Model (TESOM), Overview and Spectal Features, BNL 26456, August 1979.

4. W. Marcuse, L. Bodin, E. A. Cherniavsky, Y. Sanborn, "A Dynamic Time Dependent Model for the Analysis of Alternative, Energy Policies," Operational Research '.75, K. B. Haley, ed., North Holland Publishing Company, 1976.

5. Robert J. Condap, "Market. Penetration of Energy Supply Technologies," Department of Operations Research, Stanford University, November 1979, (preliminary draft report). 
Appendix A

The input information required for both models falls into seven.general categories: (1) supply and demand efficiencies; (2) costs; (3) environmental impact factors; (4) resource avallabilitles; (5) basic energy demands; (6) permitted market penetration; and (7) demand load characteristics of all electric service demands by season and time of day.

\section{Efficiencies}

The supply efficiencles, which relate intermediate energy forms to primary resources, include refining efficiencies, electric conversion, transmission and distribution efficiencies, and synthetic fuel manufacturing cfficlencies. A refining efficiency represents a combined extraction, cleaning, and transportation efficiency and is defined as the ratio nf the useful onergy content of the fuel derived to the user to the energy content at the minemouth or wellhead. In addition to these supply efflciencies, effective end-use utilization efficiencies must be sperified for each utilizing devicr.

Cost

The costs considered include plant capital costs, operation and maintenance costs, transmission and distribution costs, resource costs, and end-use device costs. Capital recovery costs are associated with each individual electric supply category and end-use device. Also specified is a maximum utilization factor. The actual capacity factor is determined by the model and is related to the load factor of the demands served by each technology.

\section{Environment}

Environmental impacts are associated with each of the processes in the various fuel trajectories from primary resource supply to end-use. The total. impacts for each activity are calculated and summed up along each of the trajectories.

A few of the impacts included in the models are the levels of $\mathrm{CO}, \mathrm{CO}_{2}$, $\mathrm{NO}_{\mathrm{x}}, \mathrm{SO}_{2}$, particulates and hydrocarbons. The models also calculate the curies of radioactive waste and thermal wastes generated hy plertric convoreion stations.

\section{Constraints}

There are six maln categories nf ronstraint equations ueed in the modcls.

(1) Energy conservation process equations balance the energy content of fuels into a process with the energy content of fuels out from the process including energy losses.

(2) Supply equations limit the amount of a given resource in terms of the energy content of the primary fuel (minemouth and wellhead) input to that supply category. For synthetic fuels and pumped storage, the supply constraint equations represent the energy content of the synthetic fuel after manufacturing. 
(3) Demand equations specify the level of nonsubstitutable functional end-use energy demands; each basic energy demand is defined as the amount of energy required to support an energy utilizing activity (e.g., residential space heat) assuming that the energy could be used at $100 \%$ technical effictency (after conversion). Basic energy demands are specifled for each of the demand categorles.

(4) Electrical supply and demand load characterization equations limit the electrical generating capacity of plant types as weil as accounting for peak electric demands and energy balances. The load characterization equations relate the type and quantity of electric generating capacity to the demand load characteristics of each demand type by season and time of day.

(5) Environmental constraints limit emissions of various types, such as $\mathrm{SO}_{2}$ or particulates. However, in most model runs these constraints are nonbinding and serve only to sum up environmental effluents.

(6) Market penetration equations 1imit the technology penetration of technologies and relate to rolnimum or maximum levels of fuel use or permitted capacity of a particular type. 